\title{
Produção de serapilheira em mata ciliar nativa e reflorestada no alto São Francisco, Minas Gerais
}

\author{
Flávia Peres Nunes ${ }^{1,3}$ \& Maria Tereza Cândido Pinto ${ }^{2}$ \\ Biota Neotropica v7 (n3) - http://www.biotaneotropica.org.br/v7n3/pt/abstract?article+bn01507032007 \\ Recebido em 04/10/06 \\ Versão Reformulada recebida em 21/08/07 \\ Publicado em 06/09/07 \\ ${ }^{1}$ Programa de Pós-graduação em Ecologia, Conservação e Manejo da Vida Silvestre, \\ Instituto de Ciências Biológicas - ICB, \\ Universidade Federal de Minas Gerais - UFMG, \\ Av. Antônio Carlos, 6627, Pampulha, CEP 31270-901, Belo Horizonte, MG, Brasil \\ ${ }^{2}$ Instituto de Ciências Biológicas e da Saúde, PUC-Minas, Av. Dom José Gaspar, 500, \\ Coração Eucarístico, Belo Horizonte, MG, Brasil, http://www.pucminas.br/ \\ ${ }^{3}$ Autor para correspondência: Flávia Peres Nunes, \\ e-mail: flaviaperesnunes@yahoo.com.br,http://www.icb.ufmg.br/
}

\begin{abstract}
Nunes, F.P. \& Pinto, M. T. C. Litterfall in natural and reforested gallery forests along the upper São Francisco river, Minas Gerais. Biota Neotrop. Sep/Dez 2007 vol. 7, no. 3. http://www.biotaneotropica.org.br/ v7n3/pt/abstract?article+bn01507032007. ISSN 1676-0603.

Two tracts of gallery vegetation in the upper Rio São Francisco, Minas Gerais, were studied aiming to verify differences in litterfall. Litter was collected from September 2001 to August 2002, using ten $0.25 \mathrm{~m}^{2}$ sized litter traps in each tract. Results demonstrated an elevated litterfall in both forest tracts, and that leaves predominated over branches and reproductive structures. The native forest displayed a seasonal pattern of leaf litterfall, while the reforested tract showed no such seasonal pattern for leaf litterfall. The results obtained in this study are in accordance with the values obtained in other studies conducted in forests located on tropical fluvial floodplains. The large differences in the periods of greatest litterfall production between the native forest and the reforested area appear to reflect the flora composition and the stage of succession of the species present in the tracts of vegetation studied.

Keywords: gallery forest, reforestation, São Francisco river basin, rehabilitation of degraded areas, environmental conservation.

\section{Resumo}

Nunes, F.P. \& Pinto, M. T. C. Produção de serapilheira em mata ciliar nativa e reflorestada no alto São Francisco, Minas Gerais. Biota Neotrop. Sep/Dez 2007 vol. 7, no. 3. http://www.biotaneotropica.org.br/v7n3/ pt/abstract?article+bn01507032007. ISSN 1676-0603.

Foram estudados dois trechos de vegetação ciliar na região do Alto São Francisco, Minas Gerais, com o objetivo de verificar diferenças na produção de serapilheira. A serapilheira foi coletada entre setembro/2001 e agosto/2002, utilizando-se 10 coletores de $0,25 \mathrm{~m}^{2}$ em cada trecho. Os resultados obtidos demonstraram uma produção elevada de serapilheira em ambos os trechos de mata, sendo que as folhas predominaram sobre os ramos e estes sobre os órgãos de reprodução nos dois talhões. A mata nativa apresentou um comportamento sazonal de queda de serapilheira, se contrapondo ao reflorestamento, que não apresentou sazonalidade para a queda de serapilheira. Os resultados obtidos estão de acordo com os valores próprios das matas localizadas sobre planícies aluvionares tropicais. Foram encontradas grandes diferenças entre os períodos de maior produção de serapilheira entre a mata ciliar nativa e a reflorestada, para o que estariam agindo de forma conjunta à dinâmica a florística e o estádio sucessional das espécies existentes nos trechos de vegetação estudados.

Palavras-chave: mata ciliar, reflorestamento, bacia do rio São Francisco, recuperação de áreas degradadas, conservação.
\end{abstract}




\section{Introdução}

A drástica eliminação das matas ciliares e a fragmentação das florestas, verificadas no Brasil e aceleradas nas últimas décadas, têm causado um aumento significativo dos processos de erosão dos solos, com prejuízo à hidrologia regional, evidente redução da biodiversidade e a degradação de imensas áreas submetidas a estas ações antrópicas (Barbosa 2000). No estado de Minas Gerais, grande parte da vegetação ciliar foi eliminada em função de atividades antrópicas, o que dificulta a implementação de estratégias de conservação dos recursos hídricos, uma vez que para assegurar a manutenção da qualidade do ecossistema aquático é essencial a preocupação com a vegetação ciliar. Esta formação florestal é extremamente importante para a manutenção da qualidade ambiental dos rios, funcionando como filtro, retendo poluentes que seriam carreados para o curso d'água, afetando diretamente a quantidade e a qualidade da água e, consequentemente, a fauna aquática e os recursos pesqueiros (Martins 2001). Embora a mata ciliar, devido à sua localização e importância peculiares, tenha papel fundamental na estruturação e dinâmica das áreas de contato entre os ambientes terrestres e aquáticos (Naiman et al. 1989, Naimam \& Dechamps 1990), continua a ser devastada, principalmente sob pressão da expansão agro-industrial, apesar de contar com proteção legal aos níveis federal e estadual (Aidar \& Joly 2003).

Atualmente, frente ao crescente ritmo da degradação ambiental, tem sido constatado um grande avanço na pesquisa científica e nos projetos de recuperação de matas ciliares. Grandes empresas privadas e estatais do setor energético têm contribuído para o desenvolvimento de metodologias de recuperação de matas ciliares, principalmente através de projetos de revegetação das margens dos reservatórios de suas usinas hidrelétricas (Martins 2001). Entretanto, em vista da grave condição de preservação das matas ciliares, com o conseqüente comprometimento da qualidade ambiental das bacias hidrográficas, é urgente o desenvolvimento de modelos que visem não só a recuperação da vegetação ciliar, mas que considerem a reabilitação de suas características estruturais e funcionais, relacionadas à estabilidade do solo e margens dos cursos d'água, retenção de poluentes e sedimentos, hábitat para ocupação de espécies animais, além do fornecimento de alimento e abrigo para a fauna aquática, através da serapilheira despejada pelas árvores ao solo ou carreada diretamente para o curso d'água. Nesse contexto, o estudo da produção de serapilheira tem sido recomendado para avaliar o estado de conservação ambiental de fragmentos florestais nativos ou reflorestados, por se tratar de um processo essencial na restauração e manutenção da fertilidade do solo, pois é o principal caminho para a ciclagem de matéria orgânica e nutrientes, capazes de conferir maior estabilidade ao sistema (Jordan \& Kline 1972).

A serapilheira representa a reserva central de elementos minerais e orgânicos em ecossistemas de florestas tropicais, onde os solos são quimicamente pobres e sua decomposição possibilita que os elementos liberados da biomassa vegetal entrem no sistema (Martius et al. 2004). A importância de se avaliar essa produção está na compreensão dos reservatórios e fluxos de nutrientes nos ecossistemas, os quais constituem-se na principal via de fornecimento de nutrientes, por meio da mineralização dos restos vegetais, desempenhando importante papel na formação e manutenção da fertilidade do solo, bem como na oferta de matéria orgânica para a flora e fauna local (Souza \& Davide 2001). Além disso, no estudo da ciclagem de nutrientes, a quantificação das reservas minerais e orgânicas e suas transferências entre compartimentos são de extrema importância para comparar ecossistemas em diferentes estados de conservação, assegurando a manutenção da vegetação (Coelho \& Borges 2005), constituindo um elemento chave para o sucesso nos programas de recuperação desses ambientes. Especialmente em reflorestamentos ciliares, o estudo da ciclagem de nutrientes minerais e orgânicos, via serapilheira, tem sido utilizado para verificar o sucesso do plantio, pois é o meio mais importante de transferência de elementos essenciais das plantas para o solo, garantindo a disponibilidade de nutrientes para o desenvolvimento da floresta (Vital et al. 2004). Dessa forma, além de representar um elo fundamental no fluxo de energia e matéria entre o meio físico e o biótico, a serapilheira produzida pela vegetação confere ao ecossistema do qual faz parte maior estabilidade, sofrendo uma variação de acordo com o seu estado sucessional (Olson 1963, Oliveira \& Neto 1999).

O presente trabalho teve como objetivo a quantificação da produção de serapilheira, em dois trechos de vegetação ciliar, um nativo e outro reflorestado, na região do Alto São Francisco, de forma a subsidiar o aprimoramento das estratégias de recuperação de matas ciliares nas regiões marginais dos cursos d'água do rio São Francisco.

\section{Material e Métodos}

O presente trabalho foi desenvolvido em dois trechos de mata ciliar, um nativo e outro implantado, distantes aproximadamente 30 km, localizados no município de Lagoa da Prata, na região do alto São Francisco, em Minas Gerais (Figura 1).

$\mathrm{O}$ trecho de mata nativa, utilizado como área-testemunho, foi representado por uma mata mesófila semi-decídua, a Mata do Urubu ( $19^{\circ} 54^{\prime} \mathrm{S}$ e $\left.45^{\circ} 33^{\prime} \mathrm{W}\right)$, secundária, formada por um segmento florestal isolado em avançado estado de regeneração, inserido às margens do rio São Francisco, entre grandes extensões de canaviais e pastagens. Espécies pioneiras, como Cecropia pachystachya, são observadas em áreas de clareira no seu interior, ao lado de exemplares de grande porte, característicos de estágio sucessional clímax, como Hymenea coubaril, Ficus gomeleira, Copaifera langsdorffi. A altura do dossel atinge de 12 a $15 \mathrm{~m}$ e abriga um grande número de lianas. Dentre as espécies de maior importância (IVI), destacam-se Alchornea sp., Trichilia clausseni e Ficus gomeleira (Barreto 2002).

O trecho de vegetação ciliar implantada correspondeu ao Reflorestamento da Fazenda Capoeira da Cana, localizado na margem direita do rio Santana $\left(20^{\circ} 05^{\prime} \mathrm{S}\right.$ e $\left.45^{\circ} 35^{\prime} \mathrm{W}\right)$, um importante tributário do rio São Francisco, em uma área de propriedade da Usina Açucareira Luciânia. O plantio, em substituição a canaviais aí anteriormente existentes, foi realizado há 10 anos, com 16 espécies provenientes de viveiros da região, na maioria não pertencentes às matas ciliares (Barreto 2002): Anacardium occidentale, Caesalphinia ferrea, Delonix regia, Mangifera indica, Persea gratissima, Spondias sp., além de frutíferas. Bauhinia variegata e Morus nigra se sobressaem das demais, pelo seu elevado número de representantes. Exemplares com 6 a $8 \mathrm{~m}$ de altura e $30 \mathrm{~cm}$ de circunferência à altura do peito (CAP) predominam no talhão, mas espécimens de até $18 \mathrm{~m}$ de altura e $80 \mathrm{~cm}$ de circunferência podem ser vistos em pontos esparsos no seu interior.

Ambos os trechos de vegetação ciliar localizam-se sobre areias finas e argilas sílticas laterizadas das Coberturas Dentríticas do Super Grupo Bambuí, que formam a planície de inundação na qual se inserem o rio São Francisco e tributários. A topografia da região é caracterizada pela área rebaixada que acompanha a drenagem do rio, com formas aplainadas e superfícies onduladas da Depressão Sanfranciscana, delimitadas nas bordas externas pelos Planaltos Dissecados do Centro-sul e Leste de Minas Gerais. Os solos predominantes, Latossolo Vermelho Escuro e Cambissolo, sustentam uma vegetação de cerrado, entremeada por grandes extensões de campo, mata capoeira (CETEC 1983), plantios de pastagens, monocultura de cana-de-açúcar e, em menor extensão, por áreas de cultivos anuais.

O clima local foi caracterizado durante o período de estudos por dados obtidos junto à Estação Meteorológica da Rural Canavieira Ltda., situada nas proximidades do Reflorestamento da Fazenda Capoeira da Cana: clima úmido, com precipitação total de $1418 \mathrm{~mm}$, apresentando 


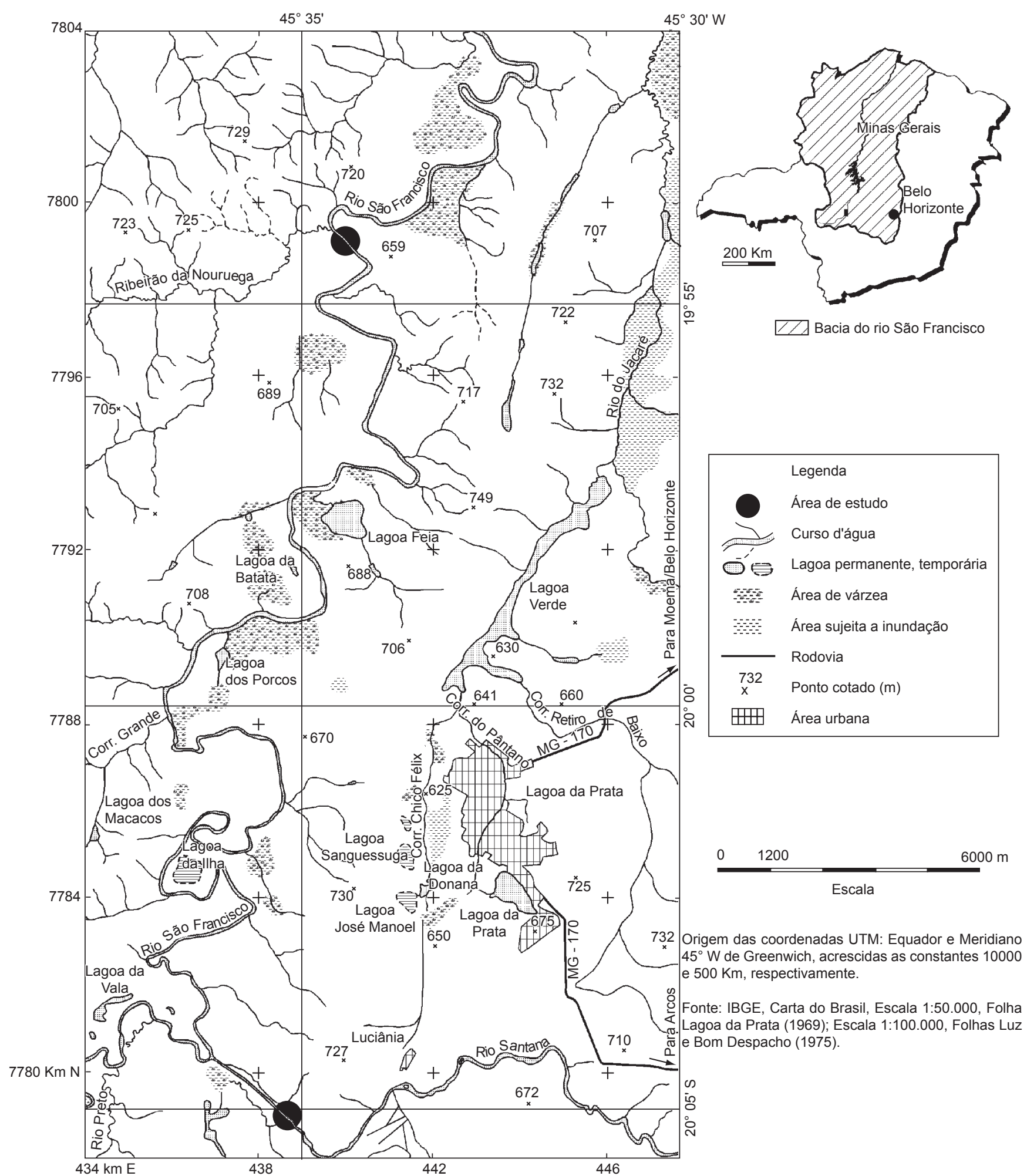

Figura 1. Áreas de Estudo (Reflorestamento da Fazenda Capoeira da Cana e Mata do Urubu), no alto São Francisco, em Lagoa da Prata, no estado de Minas Gerais.

Figure 1. Study areas (Reflorestamento da Fazenda Capoeira da Cana and Mata do Urubu) on the upper São Francisco river, in Lagoa da Prata, Minas Gerais state.

chuvas mais intensas durante o verão, atingindo a máxima mensal de $287 \mathrm{~mm}$, se contrapondo aos baixos valores do inverno, que apresentou apenas $18 \mathrm{~mm}$ de chuva, em média. A temperatura do ar oscilou entre $10{ }^{\circ} \mathrm{C}$ no inverno e $30{ }^{\circ} \mathrm{C}$ no verão, com registros médios de $22{ }^{\circ} \mathrm{C}$, enquanto a média da umidade relativa do ar para o período foi de $75 \%$.
A sazonalidade climática foi caracterizada por duas estações distintas: uma fria e seca (inverno) e outra quente e úmida (verão), o que se justifica pelo clima tropical úmido característico da região (CETEC 1983).

Para a obtenção de dados de produção de serapilheira, foi delimitado um transecto retangular $(40 \times 400 \mathrm{~m})$ no interior das matas 
estudadas, que conteve os 10 pontos amostrais, selecionados aleatoriamente (Fisher \& Yates 1979). No campo, em cada ponto amostral, foi instalada uma caixa coletora de serapilheira, feita em madeira com $0,25 \mathrm{~m}^{2}$ de área (Pinto 1992). Mensalmente, o material produzido foi recolhido, durante o período de setembro de 2001 a agosto de 2002. A biomassa recolhida foi levada ao laboratório onde foi limpa com pincel fino e separada nas frações: folhas, ramos e órgãos de reprodução (flor, fruto e semente). Cada fração foi submetida à secagem em estufa à $70{ }^{\circ} \mathrm{C}$ e, após atingirem peso constante, foi medido seu peso seco (Bastrup-Birk \& Bréda 2004).

A comparação dos valores da biomassa total e das diferentes frações entre os dois trechos de vegetação durante o ano de estudo, foi feita através do teste $t$, com nível estatístico considerado de $\mathrm{p}<0,05$.

\section{Resultados}

A produção de serapilheira apresentou valores elevados, totalizando $15,1 \mathrm{t} \mathrm{ha}^{-1} /$ ano na mata nativa e $11,4 \mathrm{t} \mathrm{ha}^{-1} /$ ano no reflorestamento, com uma distribuição mensal diferenciada nos dois trechos de mata ciliar (Figura 2).
A mata nativa apresentou picos de produção de biomassa no fim da estação seca $\left(\right.$ setembro $=156$ g.m $\mathrm{m}^{-2} ;$ outubro $=192$ g. $\mathrm{m}^{-2}$ ), como também observado por Pinto (1992) na mata ribeirinha da planície de inundação do rio Mogi Guaçu (SP). O menor volume de serapilheira produzida pela mata nativa ocorreu no período de janeiro a junho de $2002\left(51,7 \pm 24,8\right.$ g.m $\left.{ }^{-2}\right)$ e coincidiu com a produção máxima do reflorestamento $\left(96,4 \pm 17,9\right.$ g. $\left.\mathrm{m}^{-2}\right)$, revelando o comportamento antagônico entre ambas (Figura 3).

Dentre as frações da serapilheira, a que mais contribuiu para a produção total foram as folhas, representando $67,5 \%$ do total na mata nativa e $69,4 \%$ no reflorestamento, seguidas pelos ramos, totalizando $19,1 \%$ do total na mata nativa e $23,2 \%$ no reflorestamento. A fração que menos contribuiu para a produção total foram os órgãos de reprodução, representando $13,4 \%$ do total na mata nativa e $7,4 \%$ no reflorestamento. A queda de órgãos de reprodução ao solo acompanhou a das folhas, nos dois talhões, com picos de produção medidos entre o fim da estação seca e início da chuvosa.

A comparação da produção de serapilheira total entre a mata nativa e o reflorestamento (Figura 3) revelou que as produções de serapilheira total e de folhas na mata nativa foram significativamente maiores do que no reflorestamento $(\mathrm{p}<0,05)$ no período de setembro a dezembro/2001 e de julho a agosto/2002.
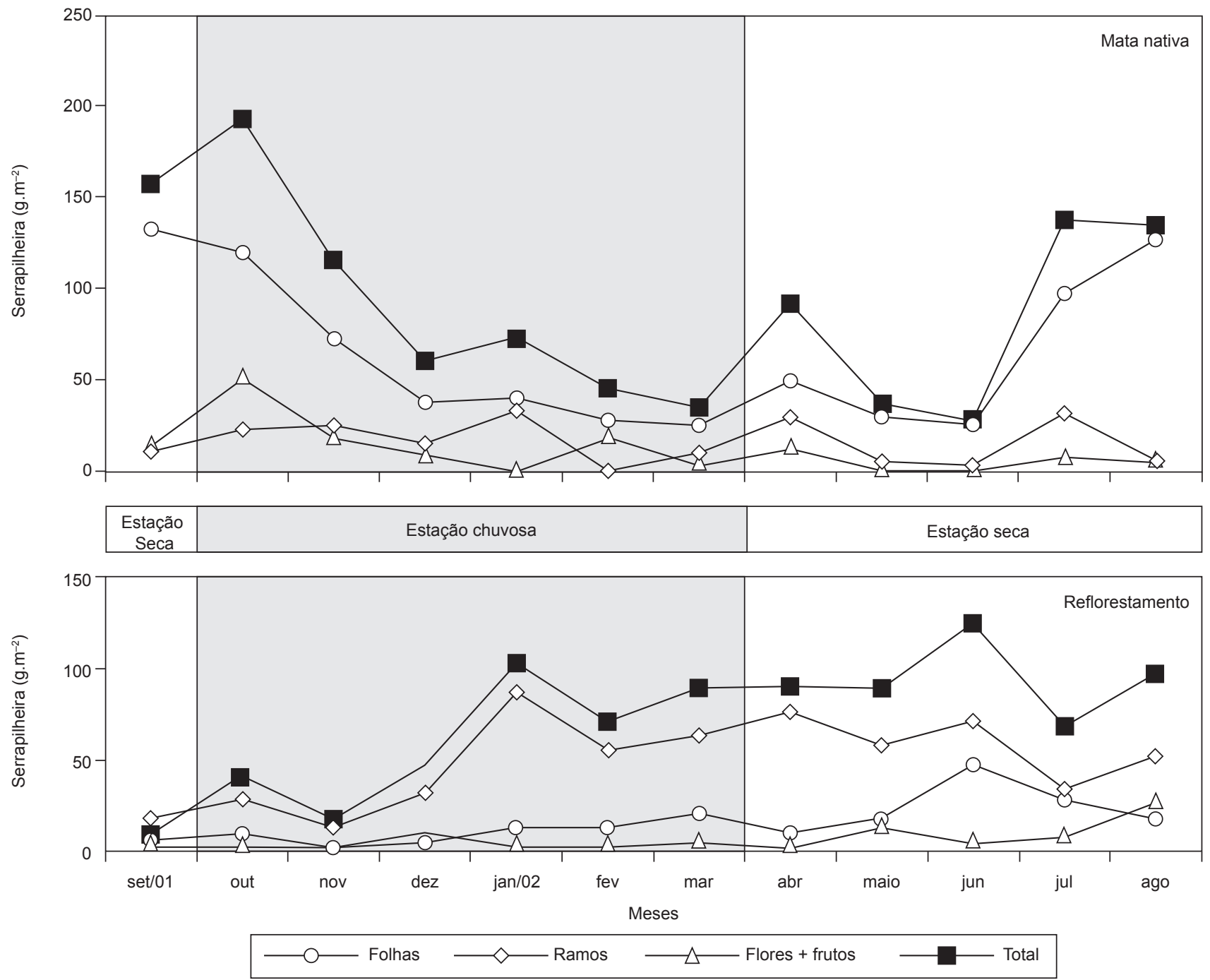

Figura 2. Produção mensal $\left(\mathrm{g} \cdot \mathrm{m}^{-2}\right)$ da serapilheira total e de suas frações na mata ciliar nativa do Urubu e no Reflorestamento da Fazenda Capoeira da Cana.

Figure 2. Total litterfall and fractions $\left(\mathrm{g} . \mathrm{m}^{-2}\right)$ in natural gallery forest of Urubu and Reflorestamento da Fazenda Capoeira da Cana. 


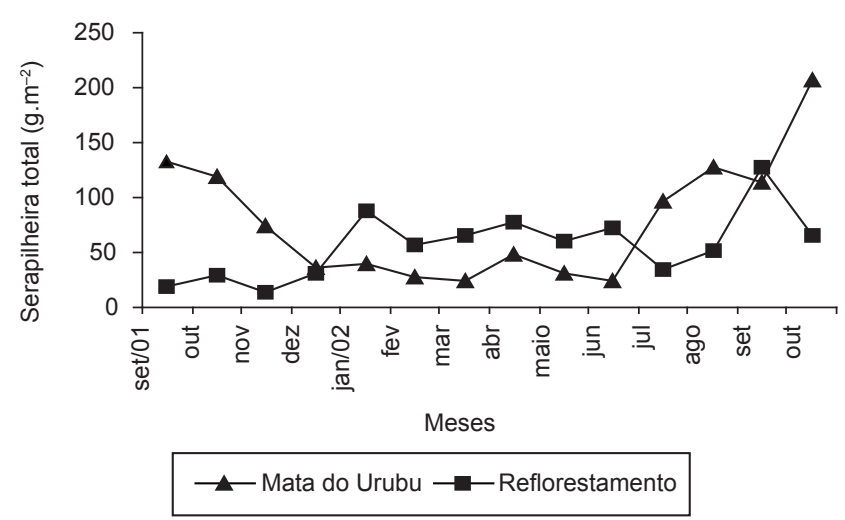

Figura 3. Produção mensal $\left(\mathrm{g} \cdot \mathrm{m}^{-2}\right)$ da serapilheira total na mata ciliar nativa do Urubu e no Reflorestamento da Fazenda Capoeira da Cana, entre 09/2001 e $08 / 2002$.

Figure 3. Mensal production (g. $\mathrm{m}^{-2}$ ) of litterfall in natural gallery forest of Urubu and Reflorestamento da Fazenda Capoeira da Cana, between 09/2001 and $08 / 2002$.

\section{Discussão}

Os altos valores obtidos para a produção de serapilheira na mata ciliar nativa e reflorestada igualam-se somente aos altos registros obtidos por Golley et al. (1978), Proctor et al. (1986) e Pinto (1992) em matas ciliares localizadas em planícies aluvionares tropicais.

O trecho de mata nativa apresentou maior produção de serapilheira, como reflexo da abundância de indivíduos arbóreos com maior porte e espessura, além de dossel mais fechado. Schlitter et al. (1993) também verificaram que a produção de serapilheira era superior nos trechos com árvores mais espessas, maior volume de madeira e que tiveram um dossel mais fechado, características presentes em vegetação secundária em avançado estágio de sucessão ecológica, como na Mata do Urubu.

Diversos trabalhos (Leitão-Filho et al. 1993, Oliveira \& Neto 1999) consideram que a grande abundância de pioneiras encontradas em matas em estágio inicial de sucessão ecológica, como no Reflorestamento, é preponderante para a maior produção de serapilheira. Entretanto, embora espécies pioneiras apresentem altos padrões de produtividade, a abundância dessas espécies em vegetações em estágio inicial de sucessão ecológica, como nos reflorestamentos, parece não constituir o principal fator determinante de altas taxas de produtividade, podendo ser menos importantes que o tamanho e o porte do dossel na determinação da produção total da serapilheira (Songwe et al. 1988).

O comportamento antagônico verificado para o período de maior produção de serapilheira na mata ciliar nativa e no reflorestamento ciliar poderia estar relacionado à composição florística e ao estádio sucessional discrepante entre os talhões de vegetação estudados (Oliveira \& Neto 1999), que se fez refletir em uma sazonalidade marcada observada na mata nativa, através da queda maciça de serapilheira ao solo durante a estação seca, se contrapondo ao padrão verificado no Reflorestamento, que apresentou altos valores mensais de serapilheira total tanto na estação chuvosa como na seca.

O predomínio da fração folhas em ambos os trechos de vegetação estudados correspondeu ao esperado, encontrando respaldo na literatura científica. Segundo Pagano (1989), o predomínio das folhas sobre as demais frações da serapilheira decorre da alta diversidade em espécies das florestas tropicais. Nas planícies sazonalmente alagáveis, os picos obtidos na estação seca, seriam uma conseqüência do balanço energético expresso pela relação custo-benefício (manutenção da biomassa luxuriante produzida no verão) própria de cada indivíduo (Pinto 1992). Para o Reflorestamento, a expressiva massa de folhas reflete seu estado de sucessão ecológica, pois a elevada deposição de folhas em vegetações que apresentam distúrbios, deve-se ao rápido crescimento e renovação foliar das espécies pioneiras, canalizando os fotoassimilados em um primeiro momento à produção vegetativa (Herbohn \& Congdon 1993). Embora as folhas tenham predominado na serapilheira, diversos estudos indicam uma maior participação das folhas na massa total de serapilheira em relação ao encontrado no presente estudo (Herbohn \& Congdon 1993, Leitão-Filho et al. 1993).

A menor participação de órgãos de reprodução na serapilheira total corresponde ao encontrado em trabalhos similares, como os de Pinto (1992), Pagano (1989) e Oliveira \& Neto (1999). Valores mais baixos para a produção de estruturas reprodutivas obtidos durante o verão coincidiram com o registrado por Pinto (1992) em vegetação similar de planície alagável e pareceram decorrer da ação conjunta das chuvas e dos ventos incidentes na região nesta época do ano. A produção contínua de órgãos de reprodução tanto pela mata como pelo reflorestamento ao longo do período amostral, com valores máximos no fim da estação seca, revelou o padrão fenológico das espécies, sua biossíntese hormonal, especialmente síntese de ácido absísico (Pinto 1992), assim como as relações mantidas entre as estratégias reprodutivas dos indivíduos e o balanço hídrico do solo da planície alagável (Junk 1982).

Embora a elevada produção de serapilheira nos trechos de mata ciliar estudados tenha correspondido ao obtido em estudos desenvolvidos em matas ciliares de planícies aluvionares tropicais, a maior queda de serapilheira ao solo na estação seca na mata nativa, se contrapondo ao reflorestamento, cujos picos foram registrados na estação chuvosa, revelou o comportamento antagônico entre elas, refletindo a florística e o estádio sucessional das espécies existentes nos trechos de vegetação estudados.

\section{Referências Bibliográficas}

AIDAR, M.P. \& JOLY, C.A. 2003. Dinâmica da produção e decomposição da serapilheira do araribá (Centrolobium tomentosum Fuill. Ex Benth. Fabaceae) em uma mata ciliar, rio Jacaré-Pepira, São Paulo. Rev. Bras. Bot. 26(2):193-202.

BARRETO, G.F. 2002. A avifauna como indicador de qualidade de reflorestamentos ciliares no alto São Francisco, Lagoa da Prata, MG. Dissertação de mestrado, Pontifícia Universidade Católica de Minas Gerais, Belo Horizonte.

BARBOSA, L.M. 2000. Considerações gerais e modelos de recuperação de formações ciliares. In Matas Ciliares: Conservação e Recuperação (R.R. Rodrigues \& H.F. Leitão-Filho, coord.). FAPESP, São Paulo, p. 89-312.

BASTRUP-BIRK, A. \& BRÉDA, N. 2004. Sampling and Analysis of Litterfall. International Cooperative Programme on Assessment and Monitoring of Air Polution Effects on Forests, United Nations Economic Commission for Europe.

CETEC. 1983. Diagnóstico ambiental do estado de Minas Gerais. CETEC, Belo Horizonte.

COELHO, G.C. \& BORGES, P.A.P. 2005. Mathematical modeling of the litter decomposition an accumulation in a forest plantation: a transient case. In Proceedings of the 2005 International Symposium on Mathematical and Computational Biology (R. Mondaini \& R. Dilão, coord.). BIOMAT 2005. Whashington.

FISHER, R.A. \& YATES, F. 1971. Tabelas estatísticas para pesquisa em biologia, medicina e agricultura. EDUSP, São Paulo.

GOLLEY, F.B., MACGINNIS, J.T., ClEMENTES, R.G., CHILD, G.I. \& DUEVER, M.J. 1978. Ciclagem de minerais em um ecossistema de floresta tropical úmida. EDUSP, São Paulo. 
HERBOHN, J.L. \& CONGDON, R.A. 1993. Ecosystem dynamics at disturbed and undisturbed sites in north Queensland wet tropical rain forest. J. Trop. Ecol. 9:365-380.

JORDAN, C.F. \& KLINE, J.R. 1972. Mineral cycling: some basic concepts and their applications in a tropical rain forest. Ann. Rev. Ecol. Syst. 3:33-50.

JUNK, W.J. 1982. Amazonian floodplains: their ecology, present and potential use. Rev. Hydrob. Trop. 13:283-301.

LEITÃO-FILHO, H.F., PAGANO, S.N., CÉSAR, O., TIMONI, J.L. \& RUEDA, J.J. 1993. Ecologia da mata atlântica em Cubatão (SP). EDUNESP/EDUNICAMP, São Paulo.

MARTIUS, C., HOFER, H., GARCIA, M.V.B., ROMBKE, J. \& HANAGARTH, W. 2004. Litterfall, litter stocks and decomposition rates in rainforest and agroforestry sites in central Amazonia. Nutr. Cycl. Agroecos. 68:137-154.

MARTINS, S.V. 2001. Recuperação de Matas Ciliares. Aprenda Fácil Editora, Viçosa.

NAIMAM, R.J. \& DECHAMPS, H. 1990. The ecology and management of aquatic-terrestrial ecotones. Man and Biosphere Series, vol. 4, Parthenon Publ. Group, Paris.

NAIMAM, R J., DECHAMPS, H. \& FOURNIER, F. 1989. Role of land/inland water ecotones in landscape management and restoration: a proposal for collaborative research. Unesco, Paris.

OLIVEIRA, R.R. \& NETO, A.L.C. 1999. Produção de serapilheira e transferência de nutrientes em três estádios sucessionais sob manejo caiçara (Ilha Grande, RJ). In Anais do I Congresso da Sociedade Brasileira de Botânica, Blumenau.

OLSON, J.S. 1963. Energy storage and the balance of producers and decomposers in ecological system. Ecology 44:322-331.

PAGANO, S.N. 1989. Produção de folhedo em mata mesófila semi-decídua no município de Rio Claro, SP. Rev. Bras. Bio. 49:633-639.

PINTO, M.T.C. 1992. Dinâmica de nutrientes na mata de galeria da Lagoa do Diogo (Estação Ecológica de Jataí, Luís Antônio, SP). Tese de doutorado, Universidade Federal de São Carlos, SP.

PROCTOR, J., ANDERSON, J.M., FODGEN, S.C.L. \& VALLACK, H.W. 1986. Ecological studies in four contrasting lowland rain forests in Gunung Mulu National Park, Sarawak. Jour. Ecol. 74:455-463.

SCLITTLER, F.H.M., MARINIS, G. \& CÉSAR, O. 1993. Produção de serapilheira na floresta no Morro do Diabo, Pontal do Paranapanema, SP. Naturalis 18:135-147.

SONGWE, N.C., FASEHUN, F.E., OKALI, D.U.U. 1988. Litterfall and productivity in a tropical rains forest, southern Bankundu forest, Cameroon. Jour. Trop. Ecol. 4:25-37.

SOUZA, J.A. \& DAVIDE, A.C. 2001. Deposição de serapilheira e nutrientes em uma mata não minerada e em plantações de bracatinga e de eucalipto em áreas de mineração de bauxita. Cerne 7(1):101-113.

VITAL, A.R.T., GUERRINI, I.A., FRANKEN, W.K. \& FONSECA, R.C.B. 2004. Produção de serapilheira e ciclagem de nutrientes de uma floresta estacional semidecidual em zona ripária. Árvore 28(6):793-800. 